\title{
Part 1: System dynamics in the UK and continental Europe
}

\author{
System dynamics at Bradford University—a silver \\ jubilee review \\ G Coyle
}

System dynamics in Europe today-a review of professional infrastructure and academic programmes

$J$ Morecroft, $P$ Milling, and P Davidsen
Part 1 traces the growth and development of system dynamics in Europe over a period of 30 years. The era begins with a small band of academic pioneers in the UK and Germany in the early 1970s and ends with a network of universities and entrepreneurial commercial ventures spread across Europe and beyond in the late 1990s.

Geoff Coyle and John Morecroft 